\title{
Perancangan E-learning Sebagai Media Pembelajaran
}

\author{
Clara Febrianti ${ }^{1}$, Adjat Sudradjat ${ }^{2}$, Retno Sari $^{3}$
}

${ }^{1}$ Sistem Informasi; Sekolah Tinggi Manajemen Informatika dan Komputer Nusa Mandiri; Jl. Jatiwaringin Raya No. 02 RT 08 RW 013 Kelurahan Cipinang Melayu Kecamatan Makasar Jakarta Timur, 13620; e-mail: clarafebri20@gmail.com

${ }^{2}$ Sistem Informasi; Universitas Bina Sarana Informatika, Jl. Kramat Raya No. 98, Senen, Jakarta Pusat 10450; email: adjat.ajt@bsi.ac.id

${ }^{3}$ Teknik Informatika; Sekolah Tinggi Manajemen Informatika dan Komputer Nusa Mandiri; Jl. Jatiwaringin Raya No. 02 RT 08 RW 013 Kelurahan Cipinang Melayu Kecamatan Makasar Jakarta Timur, 13620; e-mail: retno.rnr@nusamandiri.ac.id

\begin{tabular}{ccc}
\hline Diterima & Direvisi & Disetujui \\
$05-10-2020$ & $09-11-2020$ & $15-12-2020$ \\
\hline
\end{tabular}

\begin{abstract}
Abstrak - Saat pandemi seperti ini kegiatan belajar mengajar pada SMK Pluit Raya dialihkan menjadi sistem pembelajaran secara daring, sehingga membutuhkan suatu sistem informasi yang membantu dalam proses belajar mengajar untuk memudahkan siswa dan guru berinteraksi. Perancangan e-learning pada SMK Pluit Raya diterapkan untuk mempermudah proses belajar mengajar dan meningkatkan komunikasi antara siswa dan guru. E-learning ini dibuat dengan menggunakan metode waterfall dengan enam fase, yaitu Requirement Specification, Architectural Design, Coding, Integration \& Testing, Operation \& Maintenance. E-learning dibuat dengan menggunakan bahasa pemrograman php dan html dan databasenya menggunakan MySql. Elearning diharapkan dapat membantu proses belajar mengajar pada SMK Pluit Raya yang awalnya dalam bentuk konvesional menjadi sistem informasi yang membutuhkan jaringan internet. Pembelajaran dengan menggunakan e-learning memudahkan siswa untuk dapat mengakses materi dan memudahkan pengajar dalam membuat soal dan mengoreksi tugas maupun latihan, selain itu memudakan siswa untuk berinteraksi dengan guru dalam hal berkonsultasi mengenai pembelajaran yang dianggap sukar atau tidak dimengerti.
\end{abstract}

\section{Kata Kunci: E-learning, Waterfall, SMK Pluit Raya}

Abstract - During a pandemic like this, the teaching and learning activities at SMK Pluit Raya are diverted into a bold learning system, so it requires an information system that helps in the teaching and learning process to make it easier for students and teachers A. E-learning design at SMK Pluit Raya is implemented to facilitate the teaching and learning process and improve communication between students and teachers. This e-learning is made using the waterfall method with six phases, namely Requirement Specification, Architectural Design, Coding, Integration \& Testing, Operation \& Maintenance. E-learning is made using PHP and HTML programming languages and the database uses MySql. E-learning is expected to help the teaching and learning process at Vocational High School Pluit Raya which was originally in a conventional form into an information system that requires an internet network. Learning using e-learning makes it easier for students to be able to access material and makes it easier for teachers to make questions and correct assignments and exercises, besides that it makes it easier for students to learn with teachers in terms of learning that is difficult or not.

Keywords: E-learning, Waterfall, SMK Pluit Raya

\section{PENDAHULUAN}

Di masa pandemi ini proses kegiatan belajar mengajar dialihkan menjadi pembelajaran secara daring. Sehingga membuat proses belajar mengajar menjadi kurang efektif. Dilihat dari perolehan nilai siswa selama belajar daring yang tidak stabil pada SMK Pluit Raya sehingga dirasa perlu untuk mengetahui bagaimana cara untuk meningkatkan nilai pembelajaran.

Penggunaan media pembelajaran membuat siswa dan guru mudah dalam berkomunikasi dan mendapatkan informasi dimanapun dan kapanpun (Febriannisa \& Hasugian, 2018).

E-learning merupakan sebuah sistem yang dibuat untuk memudahkan pendidik dan peserta didik berinteraksi (Susanto \& Ayu, 2017). 
E-learning memiliki kelebihan yaitu memudahkan dalam proses pembelajaran (Rahman \& Ratna, 2018), e-learning dapat dilakukan tanpa mengharuskan para siswa maupun guru untuk hadir di dalam ruang kelas (Sofyan, Jasmir, \& Irawan, 2014).

E-learning dirasa dapat mempermudah dalam penyampaian informasi. Karena dengan $e$ learning penyampaian materi yang tadinya dengan sistem konvesional berubah menjadi sistem yang didukung dengan media internet.

Permasalahan yang dapat diidentifikasi yaitu bagaimana mengatasi permasalahan belajar mengajar di masa pandemi covid-19 di SMK Pluit Raya Jakarta yang mengakibatkan, Terhambatnya proses belajar mengajar bagi siswa dan pengajar karena wabah Covid-19.

\section{METODE PENELITIAN}

Metode Penelitian yang digunakan dalam penelitian ini menggunakan kualitatif didasarkan pada siklus hidup pengembangan sistem (SDLC) dengan model waterfall. Model waterfall dinilai mampu meningkatkan kerja sistem E-learning dan dapat mengurangi kesalahan-kesalahan(Puspita, Fahmi, \& Yuningsih, 2019). Model waterfall terbagi menjadi 5 tahap yaitu :

\section{A. Analisa Kebutuhan Sistem}

Pada tahap ini dilakukan pengumpulan data terkait dengan kebutuhan sistem yang akan dibuat serta melakukan identifikasi dari data yang telah dikumpulkan.

\section{B. Desain}

Pada tahap desain melakukan proses yang fokus pada desain pembuatan program perangkat lunak mulai dari rancangan antar muka yang terdiri dari pembuatan Entity Relationship Diagram (ERD), Logical Record Structure (LRS). Pembuatan software architecture menggunakan Unified Modelling Language (UML

\section{Code generation}

Untuk mendukung pembuatan sistem ini menggunakan bahasa pemrograman hyperlink text markup languange (HTML), php dan javascript. Database management system (DBMS) menggunakan MYSQL dengan

XAMPP.

\section{Testing}

Pengujian pada program ini fokus pada logik dan fungsional untuk memastikan semua bagian sudah diuji, pada hal ini menggunakan sistem pengujian black box testing hal ini dilakukan untuk meminimalisir kesalahan (error) dan memastikan keluaran yang dihasilkan sesuai dengan yang diiinginkan.

\section{E. Support}

Dalam proses ini diupayakan pengembangan sistem yang telah dirancang terkait software dan hardware dapat dibuat maksimal agar aplikasi berjalan dengan baik.

\section{PENELITIAN TERKAIT}

Telah dilakukan penelitian sebelumnya yang berkaitan dengan penelitian ini, yaitu:

1. Pola belajar saat ini beragam cara dapat ditempuh, antara lain belajar dengan tatap muka dan belajar tanpa harus bertatap muka yang dikenal masyarakat umum dengan sebutan $e$ learning. Pembelajaran merupakan sebuah proses panjang untuk dapat membangun sumber daya manusia yang handal dan berkarakter, sehingga melahirkan individu yang baik dan mandiri untuk membangun bangsanya. Pada proses belajar dapat digunakan media elektronik dengan jaringan computer yang dapat dilaksanakan kapan saja dan dimana saja (Sismadi, Kusnadi, 2018).

2. Penelitian ini bertujuan untuk menjadikan model pembelajaran Cooperatif Learning Tipe Team Game Tournament Berbasis E-learning yang bisa menambah minat dan sikap belajar. Penelitian ini menghasilkan sistem e-learning yang dapat menarik minat dan sikap siswa untuk belajar. Di dalam e-learning dibuat semenarik mungkin agar siswa dan guru dapat berinteraksi. (Supriadi, Alfiah, Fiqri, \& Fauzan, 2019).

3. Penyampaian pelajaran lewat internet dilakukan oleh perusahaan-perusahaan e-learning dan universitas online seperti Universitas Global 21 atau University 24/7. Hal ini dikarenakan mereka ingin memperoleh jumlah pelajar yang besar dan berasal dari berbagai wilayah. Oleh karena itu, internet, internet yang memiliki jangkauan luas, menjadi pilihan media yang tepat (Syahputra, 2017).

4. Proses penerapan e-learning pada sekolah yaitu adanya faktor yang menjadi penghalang keberhasilan penggunaan e-learning sebagai media pembelajaran, seperti masalah infrastruktur, kemauan dari pihak sekolah dan siswa, kepuasaan dalam menggunakan teknologi dan lain sebagainya. Perlu dilakukan analisis kepada para siswa mengenai penerapan pembelajaran e-learning. (Oktofiyani, Anggraeni, Studi, Informasi, \& Selatan, 2016).

5. Tanpa menghilangkan proses pembelajaran antar muka, penggunaan E-Learning melengkapi kekurangan pada metode pembelajaran tersebut dengan tersedianya media yang dapat digunakan siswa untuk mendalami materi pelajaran yang terbatas dilakukan sekolah yang dapat diakses asalkan terhubung dengan jaringan internet. Selain itu sistem e-Learning yang berbasis multimedia dimana di dalamnya terdapat tampilan grafis yang menarik akan membuat siswa lebih tertarik dalam mengikuti proses pembelajaran (Novita \& Andiarni, 2019). 


\section{HASIL DAN PEMBAHASAN}

\section{a. Analisa Kebutuhan Sistem}

Berikut spesifik kebutuhan dari sistem e-learning berbasis web.

\section{Halaman Admin :}

A1. Admin dapat mengelola manajemen pengajar.

A2. Admin dapat mengelola manajemen siswa

A3. Admin dapat mengelola registrasi siswa.

A4. Admin dapat mengelola managemen kelas.

A5. Admin dapat mengelola mata pelajaran.

A6. Admin dapat mengelola manajemen tugas / quiz.

A7. Admin dapat mengelola materi

A8. Admin dapat mengelolah halaman berita.

A9. Admin dapat melakukan logout.

Halaman Pengajar :

B1. Pengajar dapat mengelola manajemen kelas yang diajar.

B2. Pengajar dapat mengelola mata pelajaran yang diajar.

B3. Pengajar dapat mengelola manajemen tugas / quiz mata pelajaran yang diajar.

B4. Pengajar dapat menambah file materi untuk siswa yang diajar.

B5. Pengajar dapat menambah halaman berita untuk siswa.

B6. Pengajar dapat merubah data pribadi.

Halaman Siswa :

C1. Siswa dapat mengerjakan tugas / quiz yang diberikan oleh pengajar.

C2. Siswa dapat melihat nilai dari hasil tugas / quiz yang telah dikerjakan.

C3. Siswa dapat mendownload file materi yang di buat oleh pengajar.

C4. Siswa dapat melihat halaman berita yang telah dibuat admin ataupun pengajar.

C5. Siswa dapat merubah data pribadi.

\section{b. Desain}

Pada tahap desain dibuat use case diagram admin yang dapat dilihat pada gambar 1 , use case diagram pengajar pada gambar 2 dan use case diagram siswa pada gambar 3. Serta dibuat Entity Relationship Diagram (ERD) dan Logical Record Structure (LRS). ERD dapat dilihat pada gambar 4 dan LRS pada gambar 5 .

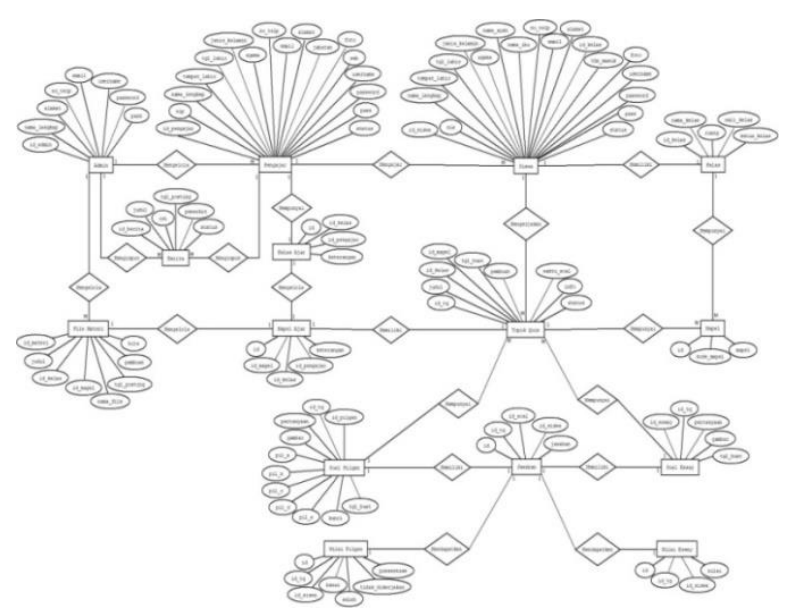

Sumber : (Hasil Rancangan, 2020)

Gambar 4. Entity Relationship Diagram (ERD)

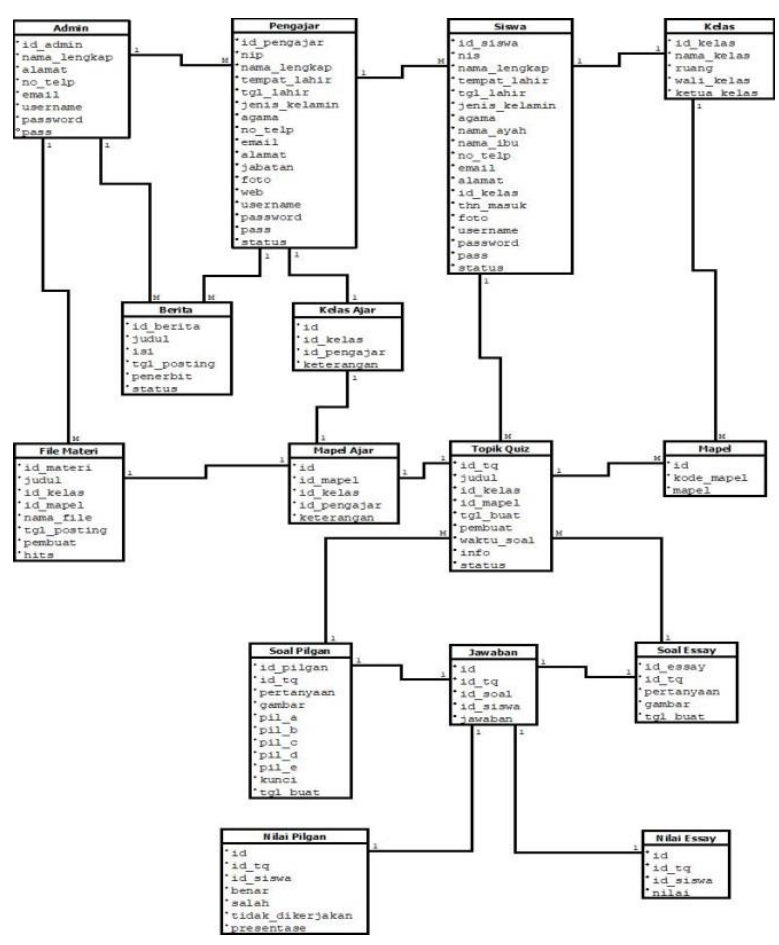

Sumber : (Hasil Rancangan, 2020)

Gambar 5. Logical Record Structure (LRS)

\section{1) User Interface}

User interface merupakan tampilan sebuah sistem yang digunakan sebagai sarana komunikasi antara user dan sistem. 


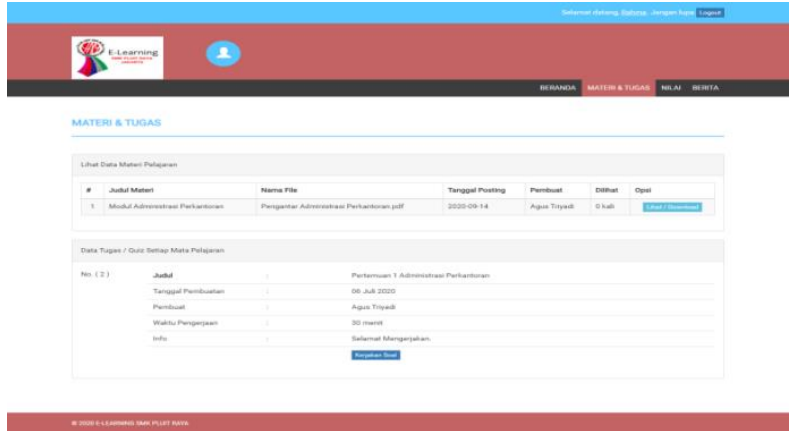

Sumber : (Hasil Rancangan, 2020)

Gambar 6. Halaman Materi \& Tugas

Halaman nilai ini berfungsi sebagai halaman untuk melihat dan mencetak nilai.

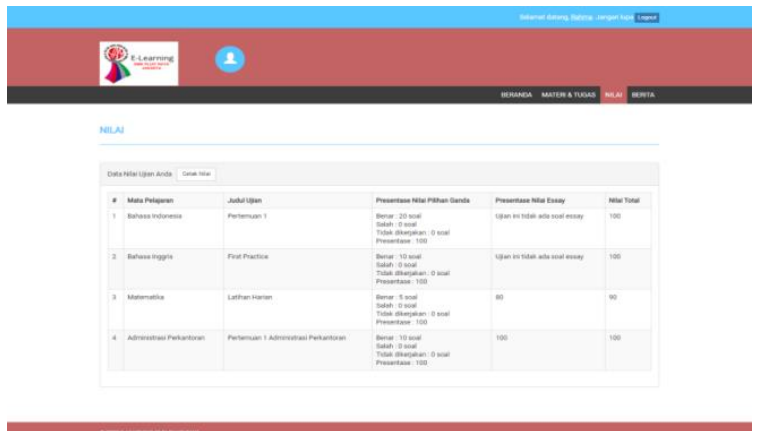

Sumber : (Hasil Rancangan, 2020)

Gambar 7. Halaman Nilai

\section{c. Code Generation}

Untuk mendukung pembuatan sistem ini menggunakan bahasa pemrograman berbasis objek, hyperlink text markup languange (HTML), php dan java script.

\section{d. Testing}

Untuk pengujian menggunakan blackbox testing. Berikut tabel blackbox testing pada halaman form siswa pada tabel 1.

Tabel 1. Blackbox testing form halaman siswa

\begin{tabular}{|c|c|c|c|}
\hline $\begin{array}{l}\text { Skenario } \\
\text { Pengujian }\end{array}$ & Test Case & $\begin{array}{l}\text { Hasil Yang } \\
\text { Diharapkan }\end{array}$ & $\begin{array}{c}\text { Hasil } \\
\text { Pengujia } \\
\mathrm{n}\end{array}$ \\
\hline $\begin{array}{l}\text { Siswa } \\
\text { mengerjaka } \\
\mathrm{n} \\
\text { Tugas/quiz }\end{array}$ & $\begin{array}{l}\text { Mengklik } \\
\text { botton } \\
\text { "kerjakan } \\
\text { soal" }\end{array}$ & $\begin{array}{c}\text { Sistem akan } \\
\text { menampilka } \\
\mathrm{n} \text { form } \\
\text { kerjakan soal }\end{array}$ & $\begin{array}{c}\text { Sesuai } \\
\text { Harapan }\end{array}$ \\
\hline $\begin{array}{c}\text { Siswa } \\
\text { melihat } \\
\text { materi } \\
\text { pelajaran }\end{array}$ & $\begin{array}{l}\text { Mengklik } \\
\text { button } \\
\text { "lihat / } \\
\text { download } \\
\text { " }\end{array}$ & $\begin{array}{c}\text { Sistem akan } \\
\text { menampilka } \\
\text { n form } \\
\text { melihat / } \\
\text { mendownloa } \\
d \\
\end{array}$ & $\begin{array}{c}\text { Sesuai } \\
\text { Harapan }\end{array}$ \\
\hline $\begin{array}{c}\text { Siswa } \\
\text { melihat } \\
\text { nilai }\end{array}$ & $\begin{array}{l}\text { Mengklik } \\
\text { botton } \\
\text { "Cetak } \\
\text { nilai" }\end{array}$ & $\begin{array}{c}\text { Sistem akan } \\
\text { otomatis } \\
\text { mencetak } \\
\text { nilai }\end{array}$ & $\begin{array}{c}\text { Sesuai } \\
\text { Harapan }\end{array}$ \\
\hline
\end{tabular}

\section{KESIMPULAN}

Kesimpulan dari penelitian yang berjudul perancangan e-learning untuk media pembelajaran yaitu e-learning dapat membantu proses belajar mengajar jarak jauh serta mampu menjangkau penyebaran informasi secara luas, cepat dan tepat dan memudahkan para pengajar dalam kegiatan belajar mengajar tanpa harus membuang waktu yang lama.

\section{REFERENSI}

Febriannisa, D., \& Hasugian, L. P. (2018), Perancangan E-learning pada SMK Negeri 1 Bandung. Jurnal ULTIMA InfoSys : JURNAL ILMU SISTEM INFORMASI, 8(2), 62-68. https://doi.org/10.31937/si.v8i2.613

Novita, A., \& Andiarni, A. (2019). PROTOTIPE ELEARNING UNTUK PENDALAMAN DAN EVALUASI MATERI PEMBELAJARAN PADA SMPN 1 SAMIGALUH. Jurnal Ilmu Pen, 4(2), 211-216.

Oktofiyani, R., Anggraeni, W., Studi, P., Informasi, S., \& Selatan, J. (2016). PENERIMAAN SISTEM E-LEARNING MENGGUNAKAN TECHNOLOGY ACCEPTANCE MODEL ( TAM ) STUDY KASUS SISWA / I KELAS X DI SMU NEGERI 92 JAKARTA. (1), 46-53.

Puspita, A., Fahmi, M., \& Yuningsih, Y. (2019). Perancangan Dan Pembuatan Aplikasi ELearning Menggunakan Model Waterfall Pada Sekolah Menengah Atas. Jurnal Riset Informatika, $\quad 1(4), \quad 173-180$. https://doi.org/10.34288/jri.v1i4.94

Rahman, F., \& Ratna, S. (2018). Perancangan ELearning Berbasis Web Menggunakan Framework Codeigniter. Technologia: Jurnal Ilmiah, 9(2), 95. https://doi.org/10.31602/tji.v9i2.1370

Sismadi, Kusnadi, Y. (2018). PREDIKSI TINGKAT KELULUSAN SISWA ELEARNING BERBASIS ALGORITMA FUZZY C-MEANS. 15(1), 1-6.

Sofyan, M. A., Jasmir, \& Irawan. (2014). Perancangan Aplikasi E-Learning Pada Mata Pelajaran Teknologi Infomasi Dan Komunikasi (Studi Kasus : Sman 6 Batanghari). 9(2), 244-253.

Supriadi, A., Alfiah, F., Fiqri, M., \& Fauzan, N. (2019). LEARNING MODEL OF COOPERATIVE LEARNING TYPE TEAM GAMES TOURNAMENT BASED ON ELEARNING IN SMK NUSAJAYA TANGERANG. 16(2), 105-112.

Susanto, W. E., \& Ayu, Y. G. A. (2017). Perancangan E-Learning Berbasis Web Pada SMP Negeri 3 Patuk Gunungkidul Yogyakarta. Bianglala Informatika, 5(2).

Syahputra, H. F. (2017). SISTEM INFORMASI E- 
LEARNING Di SEKOLAH. Jurnal Ilmu

Pengetahuan Dan Teknologi Komputer, 2(2),

60-65.

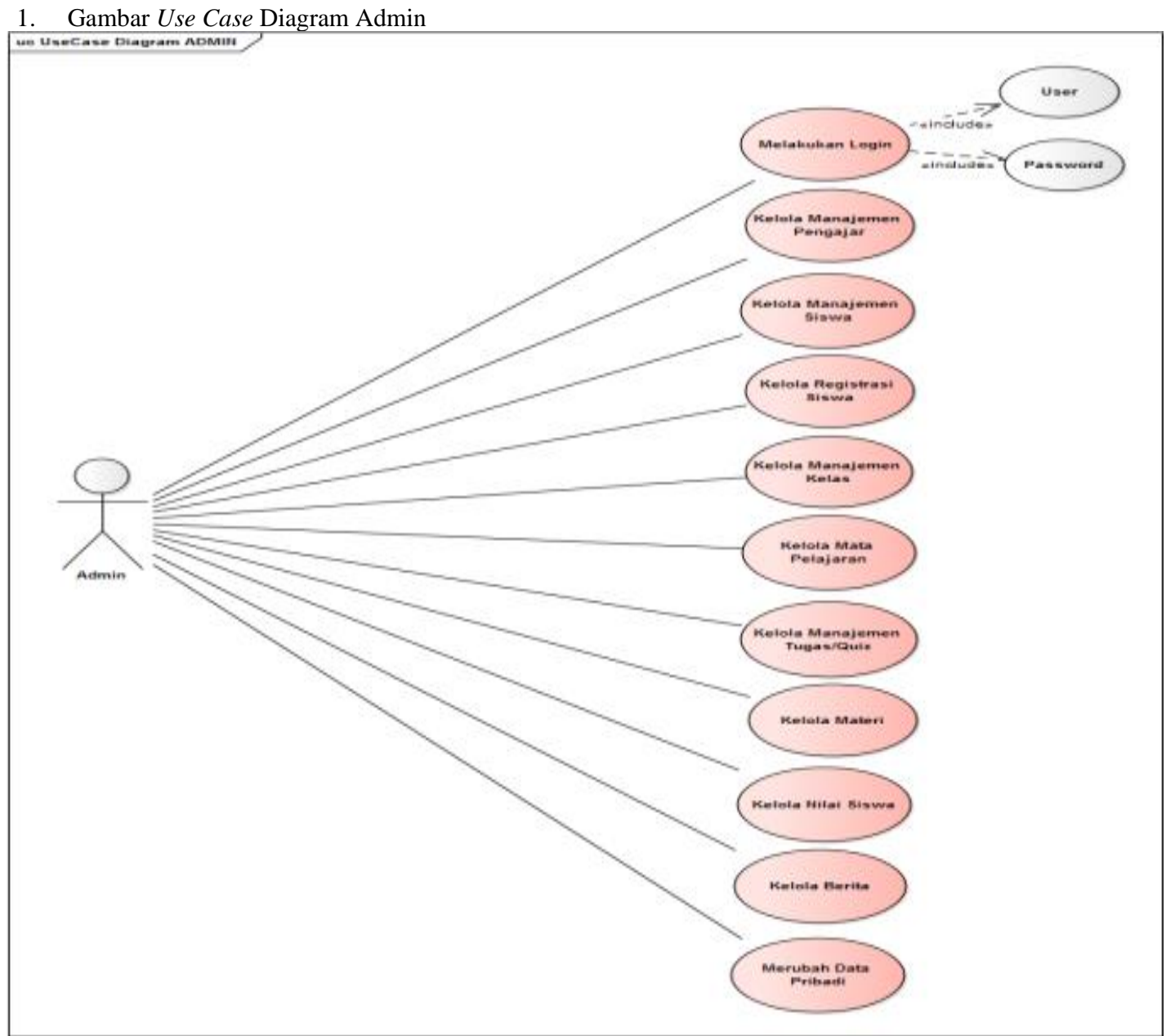

Sumber : (Hasil Penelitian, 2020)

Gambar 1. Use Case Diagram Admin 
2. Gambar Use Case Diagram Pengajar

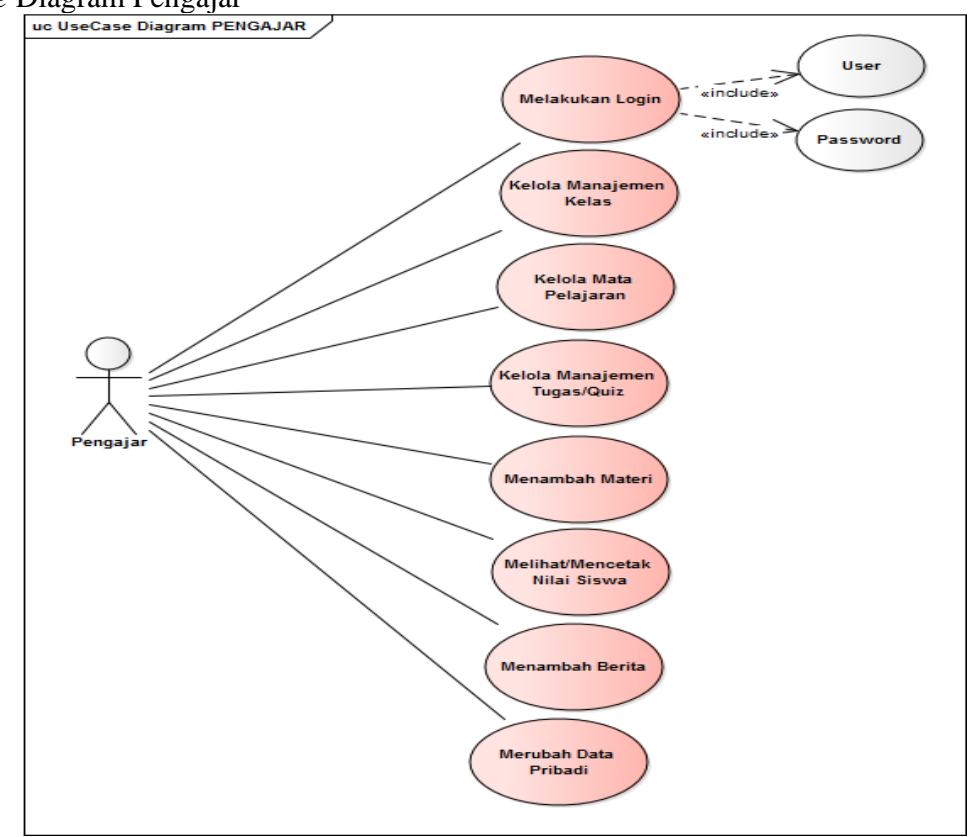

Sumber : (Hasil Penelitian, 2020)

Gambar 2. Use Case Diagram Pengajar

3. Gambar Use Case Diagram Siswa

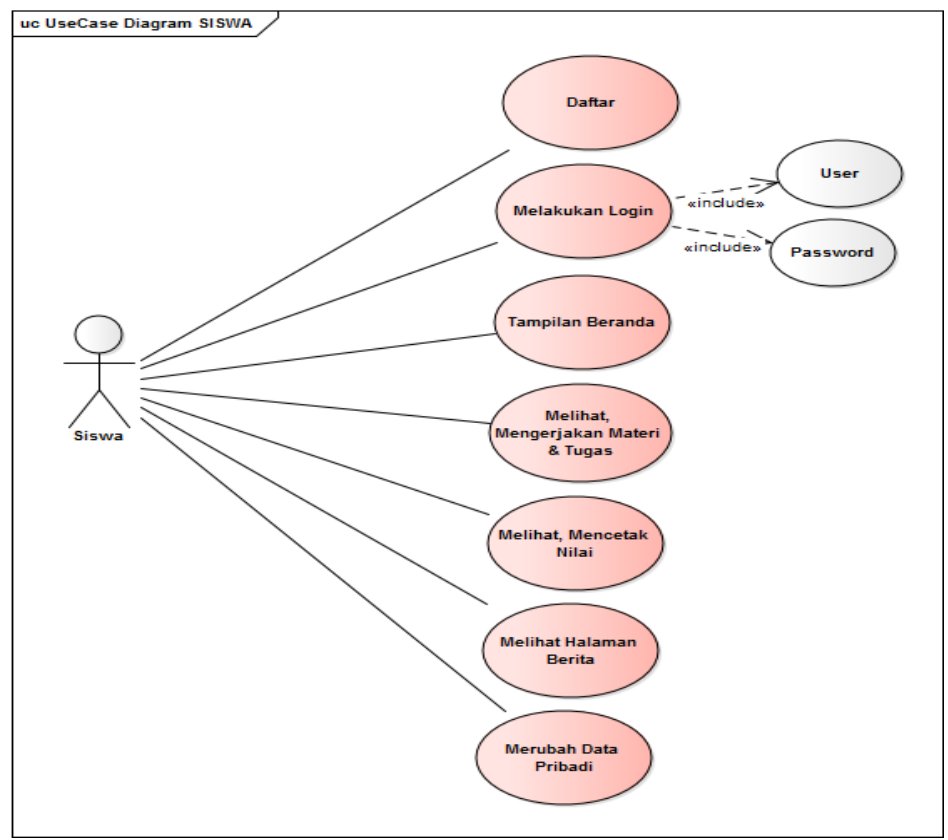

Sumber : (Hasil Penelitian, 2020)

Gambar 3. Use Case Diagram Siswa 